\title{
Interphotoreceptor retinoid binding protein is a potent tolerogen in Lewis rat: suppression of experimental autoimmune uveoretinitis is retinal antigen specific
}

\author{
Barbara Laliotou, Janet Liversidge, John V Forrester, Andrew D Dick
}

\begin{abstract}
Aims-Administration of unfractionated retinal antigen(s) (retinal extract, $R E$ ) suppresses $R E$ induced experimental autoimmune uveoretinitis (EAU) and offers a potential therapeutic alternative to nonspecific immunosuppressive therapies for posterior uveitis and autoimmune diseases. S-Ag and interphotoreceptor retinoid binding protein (IRBP) are two major autoantigens within soluble $R E$. It was aimed to assess, firstly, as has previously been shown with $\mathrm{S}-\mathrm{Ag}$, if IRBP can induce intranasal tolerance and, secondly, the contribution of both these major autoantigens to tolerance induction by whole $\mathrm{RE}$. Methods-Animals were tolerised by intranasal administration with S-Ag or IRBP, either alone or in combination, or RE before immunisation with either IRBP or RE. Control animals were administered nasally either PBS or MBP. Daily clinical responses were recorded biomicroscopically and histological grades were obtained using a semiquantitative scoring system. Weekly serum antibody levels to retinal antigens were measured by ELISA and delayed hypersensitivity responses (DTH) were assessed by skin reactivity to intradermal inoculation with retinal or non-specific antigens.
\end{abstract}

Results-Microgram doses of IRBP successfully suppressed both clinically and histologically IRBP induced EAU. This suppression was accompanied by reduced antigen specific DTH reactivity but maintained $T$ cell dependent (IgG2a) antibody responses. Furthermore, combined S-Ag and IRBP administration afforded equal suppression of RE induced EAU when compared with RE therapy alone. Suppression of RE induced EAU was not achieved with administration of a nonretinal specific autoantigen, MBP. Although individually, both S-Ag and IRBP suppressed RE induced EAU, whole RE was unable to protect against IRBP induced disease.

Conclusions-Intranasal administration of IRBP suppressed IRBP induced EAU in the Lewis rat. S-Ag and IRBP are the major contributors to the tolerogenicity within RE, despite the known uveogenicity of other retinal antigens within $R E$ and induction of tolerance was retinal antigen specific. Furthermore, suppression induced by single antigen administration is antigen specific although concomitant bystander suppression may also play a role. RE was unable to protect against IRBP induced disease despite tolerogenic levels of antigen within RE. Although this may be due in part to a dose effect of either tolerising or immunising antigen, further investigation into the possible antigen dominance of IRBP or mucosal processing of combinations of antigens is necessary so that the full efficacy of mucosal tolerance therapy can be assessed.

(Br f Ophthalmol 1997;81:61-67)

Experimental autoimmune uveoretinitis (EAU) is an organ specific $\mathrm{CD}^{+}{ }^{+} \mathrm{T}$ cell mediated autoimmune disease which is used as an investigatory model of immunotherapy ${ }^{1}$ as the model parallels well the immunopathological features of uveitis in humans. ${ }^{2}$ In an attempt to improve therapies for uveitis which are frequently limited by drug toxicity, drug resistance, and undesirable relapses on therapy, ${ }^{1}$ different approaches have been used to suppress EAU, including cyclosporin $\mathrm{A}^{3}$ and, more recently, induction of mucosal tolerance via the gastrointestinal, nasorespiratory mucosa and mucosal associated lymphoid tissue (for example, conjunctiva).$^{4-7}$ Single or repetitive doses of autoantigens are adequate to suppress many experimental models of autoimmune disease $^{8-10}$ and immunological responses to subsequent exposure to antigen. ${ }^{112}$ The mechanisms of mucosal tolerance induction are dependent upon the age of animal, dose, timing, and route of antigen administration and include $\mathrm{T}$ cell anergy, including specifically $\mathrm{CD}^{+} \mathrm{T}$ helper cell (Th1) responses, ${ }^{13}$ cytokine driven bystander suppression, ${ }^{14}{ }^{15}$ and antigen specific $\mathrm{T}$ cell suppression involving both $\mathrm{CD}^{+}$and $\mathrm{CD}^{+}{ }^{\mathrm{T}}$ cells. ${ }^{1617}$ Although all these mechanisms are well established, the relative role of each in mucosal tolerance suppression of organ specific autoimmune disease remains undefined. Despite this the promise of this form of therapy has led to the development of clinical trials in various autoimmune diseases (rheumatoid arthritis and multiple sclerosis) and some encouraging early results have been reported. ${ }^{18}$ To date, however, 
there is no conclusive experimental evidence which either shows, firstly, that oral tolerance induction can modulate an ongoing immune response or, secondly, which soluble retinal antigens may be the more potent inducers of mucosal tolerance. The latter has important therapeutic implications because it is still unknown which retinal autoantigen patients are reactive towards when they have disease relapse. In our laboratory, we have established a model of nasal tolerance induction in Lewis rats which uses only microgram doses of either $\mathrm{S}-\mathrm{Ag}$ or whole retinal extract (ineffectual quantities to induce oral tolerance) and suppresses histological disease as effectively as oral tolerance. ${ }^{619}$ This method of mucosal tolerance inhibits antigen specific delayed type hypersensitivity (DTH) responses while maintaining $\mathrm{T}$ cell dependent antibody responses, in particular IgG2a responses. ${ }^{19}$ To date, evidence for a direct role for retinal antigens in autoimmune uveoretinitis in humans remains elusive and in conjunction with the scant data in the experimental model to indicate which autoantigen(s) or, in the case of mucosal tolerance, tolerogen(s) are dominant, this report compares efficacy of another potent inducer of EAU, interphotoreceptor retinoid binding protein (IRBP), in nasal mucosal tolerance induction with S-antigen (S-Ag) and retinal extract (RE) to indicate which antigen or combinations of antigens may be employed clinically.

\section{Methods}

ANIMALS AND ANTIGENS

Inbred female Lewis rats 6-8 weeks of age (175-200 g) from the animal facility at the medical school, University of Aberdeen, were used. All experiments adhered to the ARVO statement for the use of animals in ophthalmic and vision research and Home Office regulations. Soluble bovine RE was prepared by hypotonic lysis of freshly dissected retinae in the dark as previously described. ${ }^{6}$ The procedure ensured the highest possible yields of photoreceptor antigens (S-Ag and IRBP) within the crude extract. S-Ag accounts for $4-6 \%$ and IRBP $5-10 \%$ of the total protein in $\mathrm{RE}$ preparations as measured by competitive enzyme linked immunosorbent assay (ELISA) estimation. Briefly, the proportion of antigen in $\mathrm{RE}$ was determined by incubating $\mathrm{RE}$ with either anti-S-Ag or anti-IRBP monoclonal antibody $(\mathrm{mAb})$, in parallel with dilutions of positive standards of antigen and antigen specific $\mathrm{mAb}$ incubate, and adding to solid phase of plate coated with specific antigen. After adding secondary antibody the reaction was read spectrophotometrically at $\mathrm{A}_{490}$. S-Ag was prepared from retinal homogenates and purified by high performance liquid chromatography (HPLC) on TSK-DEAE column as previously described (for cross reference; see Dick et $a l^{6}$ ). The S-Ag was homogeneous by silver staining on SDS-PAGE using Pharmacia Phast system, according to the manufacturer's instructions. IRBP was purified according to Fong et al (cross reference; see Dick et $a l^{6}$ ). Briefly, interphotoreceptor matrix was loaded onto a concanavalin-A (Con A) sepharose
Table 1 Interphotoreceptor retinoid binding protein (IRBP) suppresses clinical and histological responses in IRBP induced experimental autoimmune uveoretinitis (EAU)

\begin{tabular}{llll}
\hline Tolerising antigen & $\begin{array}{l}\text { Incidence } \\
\text { (eyes) }\end{array}$ & $\begin{array}{l}\text { Clinical } \\
\text { score }\end{array}$ & $\begin{array}{l}\text { Histological } \\
\text { score }\end{array}$ \\
\hline $\operatorname{IRBP}(50 \mu \mathrm{g} / \mathrm{ml})$ & $8 / 8$ & 1.75 & $1.6^{\star}$ \\
$\operatorname{IRBP}(10 \mu \mathrm{g} / \mathrm{ml})$ & $8 / 8$ & 2.5 & $3 \dagger$ \\
$\operatorname{RE}(4.5 \mathrm{mg} / \mathrm{ml})$ & $8 / 8$ & 2.75 & 3.25 \\
PBS & $8 / 8$ & 4 & 3.6 \\
\hline
\end{tabular}

Animals were immunised subcutaneously with $100 \mu \mathrm{g}$ of IRBP w/v complete Freund's adjuvant. Maximal clinical and histological scores represent the median score derived from separate analysis of all eyes. Median histology scores were derived 16 days after immunisation.

$\mathrm{RE}=$ retinal extract; $\mathrm{PBS}=$ phosphate buffered saline.

Statistically significant suppression of EAU histologically compared with control animals (PBS). ${ }^{\star} \mathrm{p}<0.005 .+\mathrm{p}<0.02$.

affinity chromatograph (Pharmacia, Sweden) and crude IRBP eluted using TRIS-HCl/0.15 $\mathrm{mM} \mathrm{NaCl} / 1 \mathrm{mM} \mathrm{CaCl}_{2} / 1 \mathrm{mM} \quad \mathrm{MnCl}_{2} / 0.2$ $\mathrm{mM}$ methyl-D-mannopyranoside $\mathrm{pH} \quad 7.5$ (Sigma, UK). Further purification was obtained using a sepharose high performance chromatograph (Pharmacia) and mannoseagarose affinity column (Sigma, UK) to remove contaminating Con $\mathrm{A}$.

INDUCTION OF INTRANASAL TOLERANCE

Thirty $\mu$ of either single or a combination of purified IRBP, S-Ag, RE, or control phosphate buffered saline (PBS) were directly administered intranasally using an Oxford micropipette. Full details of tolerising antigens are given in Tables 1-3. Briefly, S-Ag and IRBP were administered alone or in combination with each other. RE was always administered alone. At least four animals were included in each group. Exact numbers are again detailed in Tables 1-3. Nasal inoculations were given on weekdays for 2 weeks (10 inoculations), followed by a 1 week break before immunisation with retinal antigen (see below). Tolerance was induced with concentrations of RE between 4.5 and $5.7 \mathrm{mg} / \mathrm{ml}$ of total protein. Tolerising dose of RE consist of between 15 and $30 \mu \mathrm{g}$ of S-Ag and IRBP. When single applications of antigen were administered the tolerising doses of S-Ag were $20 \mu \mathrm{g} / \mathrm{ml}$ and IRBP between 10 and $50 \mu \mathrm{g} / \mathrm{ml}$. Total inoculum doses are detailed in the results section.

\section{INDUCTION OF EAU}

On day 21 of the experiment, animals were immunised by subcutaneous hind footpad

Table 2 S-antigen $(S-A g)$ and interphotoreceptor retinoid binding protein (IRBP) intranasal tolerance therapy suppresses $R E$ induced $E A U$ to the same extent as $R E$ tolerance therapy

\begin{tabular}{lcll}
\hline Tolerising antigen & $\begin{array}{l}\text { Incidence } \\
\text { (eyes) }\end{array}$ & $\begin{array}{l}\text { Clinical } \\
\text { score }\end{array}$ & $\begin{array}{l}\text { Histological } \\
\text { score }\end{array}$ \\
\hline RE & $16 / 16$ & 2 & $2.25 \dagger$ \\
IRBP + S-Ag* & $8 / 8$ & 1.75 & $2.13 \dagger$ \\
IRBP & $8 / 8$ & 1.25 & $2.13 \dagger$ \\
PBS & $16 / 16$ & 4 & 3.5 \\
\hline
\end{tabular}

All animals were immunised with $250 \mu \mathrm{g} /$ rat of retinal extract (RE). This table represents a combination of two experiments. $\star 20 \mu \mathrm{g} / \mathrm{ml}$ of S-Ag and $50 \mu \mathrm{g} / \mathrm{ml}$ of IRBP were used during tolerising process.

†Suppression of histological disease day 21 after immunisation, compared with control animals (phosphate buffered saline, PBS) is significant; $\mathrm{p}<0.02$. 
injection of either RE (250-290 $\mu \mathrm{g} / \mathrm{rat})$ or $\operatorname{IRBP}(100 \mu \mathrm{g} / \mathrm{rat})$ emulsified (w/v) in complete Freund's adjuvant (CFA) supplemented with $2.5 \mathrm{mg} / \mathrm{ml}$ Mycobacterium tuberculosis H37RA, but without pertussis. Clinical severity was graded by slit-lamp biomicroscopy on a scale of $0-4$ and on days 16-21 after immunisation the animals were killed and the eyes processed for histopathological examination and graded semiquantitatively (for cross reference see Dick et $\left.a l^{6}\right)$.

ELISA ASSAY AND DTH REACTIVITY

Serum antibody production was assessed weekly using a standard ELISA assay as described previously. ${ }^{6}$ Bound antibodies were detected using peroxidase conjugated rabbit anti-rat immunoglobulin (Dakopatts, Stockholm, Sweden) and enzyme substrate of $o$-phenylenediamine (Sigma, UK; $0.4 \mathrm{mg} / \mathrm{ml}$ ) in citrate buffer. The intensity of the colour reaction was read at $490 \mathrm{~nm}$ in a minireader II (Dyantech, Billinghurst, UK). Isotype IgG1, IgG2a, IgM, and IgE were measured similarly using isotype specific peroxidase conjugated rabbit anti-rat immunoglobulin (Serotec, Bicester). Skin tests were performed on day 15 post immunisation. The flanks were shaved and intradermal injections of $0.1 \mathrm{ml}$ PBS, purified protein derivative (PPD; $100 \mu \mathrm{g}$ ) and antigen IRBP $(33 \mu \mathrm{g})$ were given into separate sites. Any increase in skin thickness was measured with a Schnelltaster micrometre gauge at $4,12,24,48$ hours after injection. The extent of the swelling was calculated by subtracting the value for the PBS injected site from that of the test sites (PPD and IRBP). DTH and antibody estimations of experimental results were designated significant with a $\mathrm{p}$ value $<0.05$, by Student's $t$ test. Histological grades are represented as median scores and statistical comparison was computed using Mann-Whitney non-parametric analysis on Statworks, Apple Mac. A $p$ value of $<0.02$ was designated significant.

\section{Results}

IRBP IS AN EFFECTIVE TOLEROGEN AGAINST IRBP INDUCED EAU

We have previously shown that nasal mucosal tolerance can be induced with $\mathrm{RE}$ which protects from subsequent immunisation with $\mathrm{RE}$ and CFA. This effect displayed antigen specific suppression of DTH reactivity and tol-

Table 3 The induction of intranasal tolerance to RE induced experimental autoimmune uveoretinitis (EAU) is retinal antigen specific

\begin{tabular}{|c|c|c|c|}
\hline Tolerising antigen & $\begin{array}{l}\text { Incidence } \\
\text { (eyes) }\end{array}$ & $\begin{array}{l}\text { Median } \\
\text { clinical } \\
\text { severity }\end{array}$ & $\begin{array}{l}\text { Median } \\
\text { histological } \\
\text { score (range) }\end{array}$ \\
\hline IRBP $(50 \mu \mathrm{g} / \mathrm{ml})$ & $5 / 12$ & 0.5 & $1.5(1-3)$ \\
\hline IRBP $(1 \mu \mathrm{g} / \mathrm{ml})$ & $11 / 12$ & 1 & $2(1-3)$ \\
\hline $\mathrm{S}-\mathrm{Ag}(20 \mu \mathrm{g} / \mathrm{ml})$ & $9 / 12$ & 1 & $1 \quad(0.5-1.5)$ \\
\hline $\mathrm{MBP}(30 \mu \mathrm{g} / \mathrm{ml})$ & $12 / 12$ & 2 & $2 \quad(1-4)$ \\
\hline PBS & $10 / 12$ & 3 & $3 \quad(2-4)$ \\
\hline
\end{tabular}

Animals were immunised subcutaneously with $290 \mu \mathrm{g}$ of retinal extract w/v complete Freund's adjuvant.

Each histological score at day 21 after immunisation represents the median score derived from separate analysis of all eyes with disease. Median clinical score was derived from of all eyes in each group.

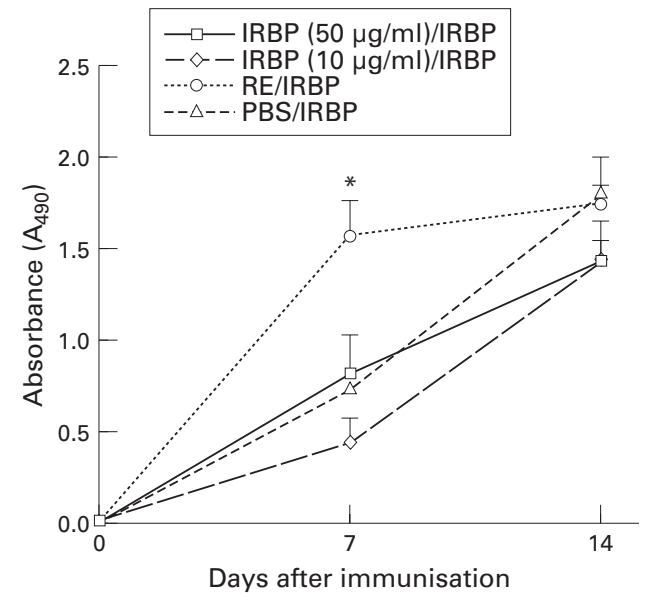

Figure 1 Antibody production in IRBP induced EAU in both controls and intranasal tolerised animals. There was no significant difference in total antibody levels (measured spectrophotometrically at $O D_{490}$ ) except the group tolerised with retinal extract (RE) which had elevated total antibody titres $\left({ }^{\star} p<0.05\right)$ on day 7 . The increased antibody titre was predominantly IgG2a isotype. In the other groups antibody isotypes were also measured (IgM, IgG2a, and IgG1) and there was again no difference between the two groups with IgG2a generating the predominant antibody response (data not shown).

erising with $\mathrm{RE}$ protected against $\mathrm{S}-\mathrm{Ag}$ induced EAU. ${ }^{619}$ Our first aim, therefore, was to determine whether IRBP could be an effective tolerogen in the Lewis rat, protecting against IRBP induced disease. Using a model of IRBP induced EAU without the use of pertussis toxin (to prevent any potential abrogation of tolerance induction $)^{20}$ an optimum immunising dose of $100 \mu \mathrm{g}$ in w/v CFA elicited a consistently severe intraocular inflammation. Animals immunised with $77 \mu \mathrm{g}, 128 \mathrm{mg}$, and $160 \mu \mathrm{g}$ of IRBP developed consistent disease in all eyes, with day of onset between 11 and 15 . We have shown with doses used in this experiment that intranasal administration of IRBP suppressed the clinical and histological inflammatory response of IRBP induced EAU when compared with sham controls. A dose of 50 $\mu \mathrm{g} / \mathrm{ml}$ of IRBP (a total tolerising dose of $30 \mu \mathrm{g}$ ) affords greater protection compared with 10 $\mu \mathrm{g} / \mathrm{ml}$ (total tolerising dose of $6 \mu \mathrm{g}$; Table 1), the former suppressing clinical disease and median histological score, which incorporated both rod outer segment (ROS) infiltration and ROS loss $(p<0.005)$. The day of onset of disease in all controls was consistently day 9 and in treated groups, although the day of onset was day 9, all animals did not develop disease until day 13. Total anti-IRBP and anti-RE antibody levels and isotypes including IgG1, IgG2a, IgM, and IgE were determined. Anti-IRBP total antibody titres showed a progressive increase which was evident from 7 days after immunisation (Fig 1). There was no significant difference in antibody levels between IRBP tolerised animals and controls, and in particular the antibody class in both groups was predominantly an antigen specific IgG2a response (data not shown). IgE was not detectable in any sera collected.

Skin tests were performed on day 15 post immunisation and there was a significant suppression of DTH response to IRBP in 


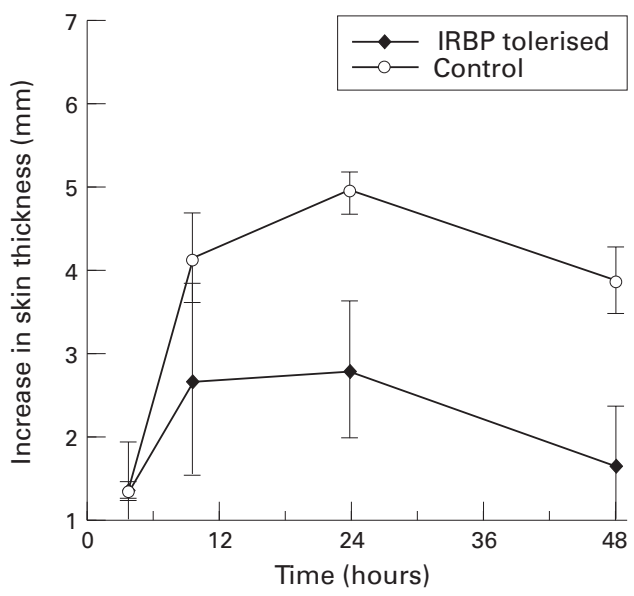

Figure 2 Delayed hypersensitivity reactivity (DTH) to retinal extract in both controls and IRBP tolerised animals in IRBP induced EAU. There was a significant reduction in $D T H$ reactivity to retinal extract $(p<0.05$ at 24 hours) in animals tolerised with IRBP. This effect appears to be retinal antigen specific as reactivity to a non-specific protein, PPD, present in complete Freund's adjuvant within the immunising cocktail was equal in both groups (data not shown).

tolerised rats (Fig 2) particularly at 24 hours $(\mathrm{p}<0.05)$, while responses to PPD were equal in both tolerised and control animals.

$\mathrm{RE}$ was unable to protect against IRBP induced EAU. Despite the observed reduced clinical inflammation, histological inflammation, and ROS destruction (target organ damage) was marked (Table 1). This was the only treated group which displayed a significant increase in total Ig levels, at day 7 post immunisation (Fig 1). In this group, the predominant antibody response was IgG2a anti-IRBP, significantly greater than controls. However, there was no difference in total anti-S-Ag response between the groups.

\section{S-AG AND IRBP ARE MAJOR TOLEROGENS WITHIN} RE

With any attempted redress of immunoregulatory networks by mucosal tolerance induction there is a delicate balance between possible exacerbation or suppression of immune responses. $^{21}$ One possible factor within this conundrum is the contribution of individual antigens. As nasal tolerance induces an antigen specific suppression of DTH response, ${ }^{19}$ we aimed to identify if combined S-Ag and IRBP or IRBP alone were sufficient tolerogens to suppress EAU induced with a variety of soluble fractions of heterologous retinal antigens (RE). We found that administering both S-Ag and IRBP intranasally significantly suppressed clinically and histologically RE induced EAU to the same extent as RE induced tolerance (Table 2). There was no difference in the humoral response (including the predominant IgG2a response) between any of the groups. Histology shows that despite cellular infiltration within the iris, ciliary body, and choroid the retinae of tolerised rats (particularly the target organ, rod outer segments) were largely protected (Fig 3C; R). Furthermore, nasal administration of IRBP alone was sufficient to suppress both clinically and histologically RE induced disease (Table 2). Suppression was also found with S-Ag intranasal administration (see below).

INDUCTION OF INTRANASAL TOLERANCE TO RE-INDUCED EAU IS RETINAL ANTIGEN SPECIFIC A total of $50 \mu \mathrm{g} / \mathrm{ml}$ (total inoculum dose of 30 $\mu \mathrm{g})$ of IRBP alone was sufficient to suppress RE induced EAU (Table 3). Although, unlike our previous experiments (Table 2) the degree of suppression did not reach statistical significance because, firstly, the incidence of disease in this group was reduced and, secondly, the histological grading scores were only derived from eyes with disease only, the experiment was representative of the suppressive activity of IRBP. A total of $1 \mu \mathrm{g} / \mathrm{ml}$ of IRBP, however, did not provide significant protection. S-Ag administered at a previously determined effective tolerising dose before immunisation ${ }^{6}$ was also successful in suppressing histological disease (Table 3). However, myelin basic protein (MBP), a potent autoantigen which induces experimental allergic encephalomyelitis, was unable to suppress histological disease.

\section{Discussion}

Induction of tolerance (immunological unresponsiveness) is a natural and powerful method of inducing suppression which occurs early during thymic development of $\mathrm{T}$ cell responses and continues into adult life (peripheral tolerance), the latter commonly being initiated through interaction with mucosal associated lymphoid tissue (MALT). Different mechanisms are involved in mediating oral tolerance depending on the dose fed (see below). We have now shown that an organ specific Th1 (DTH)-type autoimmune disease, EAU, can be successfully suppressed by inhalation of microgram quantities of retinal antigens including the two principal uveitogenic retinal proteins, S-Ag and IRBP. This study describes a model of IRBP induced tolerance to IRBP induced EAU which not only results in suppression of clinicohistological inflammation but also suppression of antigen specific DTH reactivity while $\mathrm{T}$ cell dependent antibody responses are maintained, similar to the responses found during both $\mathrm{RE}$ and $\mathrm{S}-\mathrm{Ag}$ induced tolerance.

The underlying cellular mechanisms of IRBP induced mucosal tolerance induction have yet to be elucidated fully. Recently Rizzo et $a l^{22}$ have proposed, using a murine model of autoimmunity, that the mechanisms of oral tolerance with IRBP, be it T cell anergy or active cytokine driven suppression, depend on dose of antigen fed and concomitant IL-2 levels. Oral tolerance has been described with other models, ${ }^{8-12}$ where in general it has been described that low dose feeding of antigen gives rise to TGF- $\beta$ secreting $\mathrm{CD} 8^{+} \mathrm{T}$ cell suppression or cytokine driven suppression (for example, IL-4) and high dose antigen feeding results in clonal anergy (for review see Rizzo and $\mathrm{Caspi}^{23}$ ). In the light of other data, this perhaps is an oversimplistic explanation of what is happening in vivo, which shows a fine balance between exacerbation or suppression 

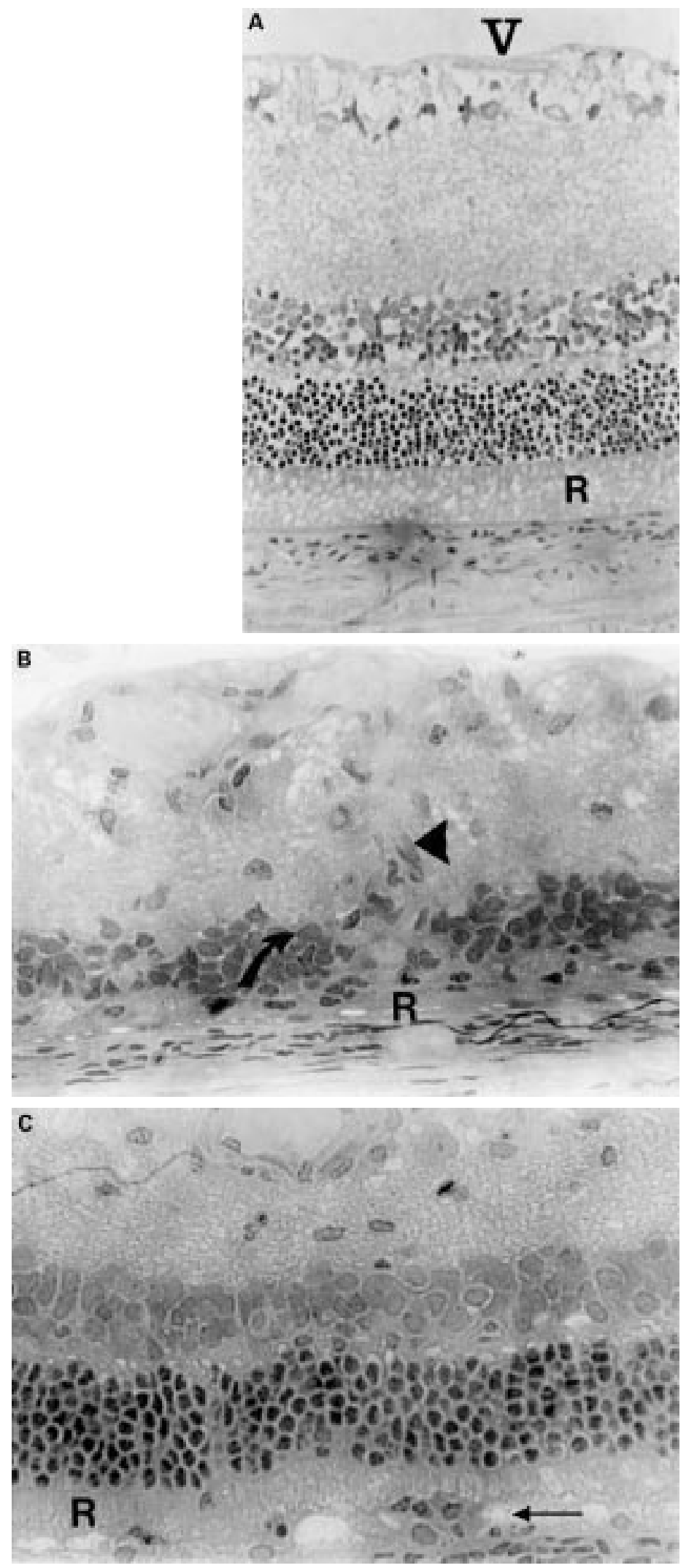

Figure 3 Administration of both $S-A g$ and IRBP intranasally protects against ROS damage in re-induced EAU. (A) Normal retinal morphology. $V=$ vitreous, $R=$ outer segments of rod photoreceptor cells (ROS). IRBP induced EAU results in a total loss of $R O S(B, R)$ and destruction of both nuclear and ganglion cell layers of the retina $(B$, arrows). These animals also demonstrated fibrovascular membrane formation (arrowhead) as a result of intraocular inflammation. Administration of both tolerising doses of IRBP and S-Ag intranasally before immunisation with RE protects the ROS $(C, R)$ although mononuclear leucocytic infiltration still occurs (C, arrow). The histological features are similar to the protection achieved with RE intranasal administration. of the immune response. For example, there is potential of MBP specific T cells to differentiate in vivo into encephalitogenic or regulatory $\mathrm{T}$ cells depending upon the context-for example, the dose and route by which they are exposed to antigen. ${ }^{21}{ }^{24}$ This apparent diverse role for $\mathrm{CD}^{+} \mathrm{T}$ cells is further supported by the finding that depletion of $\mathrm{CD} 4^{+} \mathrm{T}$ cells and not $\mathrm{CD}^{+} \mathrm{T}$ cells prevents oral tolerance induction to ovalbumin. ${ }^{17}$ Furthermore, depending on dose of antigen administered orally, deletion of both $\mathrm{Th} 1$ and $\mathrm{Th} 2 \mathrm{CD} 4^{+} \mathrm{T}$ cells is induced via apoptosis. ${ }^{25}$ Although these mechanisms are present in oral tolerance, there are important differences between oral and nasal mucosal tolerance ${ }^{26}$; firstly, dose of antigen delivered via the nasorespiratory tract is much smaller (microgram quantities of antigen) to the extent that these doses are ineffectual for oral tolerance induction. Secondly, there has been no evidence for $\mathrm{T}$ cell anergy or $\mathrm{T}$ cell deletion as a mechanism of nasal tolerance induction. Our preliminary data suggest that within regional drainage lymph nodes apoptosis of both $\mathrm{CD} 8^{+}$and $\mathrm{CD} 4^{+} \mathrm{T}$ cells may occur (unpublished results). Evidence in other experimental models suggests that nasal tolerance induction is antigen specific, transferable to naive recipients, and is mediated by either $\mathrm{CD}^{+}, \gamma \delta \mathrm{TCR}^{+}$, or $\mathrm{CD} 4{ }^{+} \mathrm{T}$ cells. ${ }^{27}{ }^{28}$ However, it should be noted at this point that any mechanism of tolerance induction is likely to be dependent upon not only the dose of antigen (see above) but also the capacity of the local mucosal lymphoid tissue to process and present different forms of antigen ${ }^{29}$ and the extent of antigen epitope spreading (presenting different determinants of the antigen) via a mechanism, similar to epitope spreading in perpetuating chronic relapsing autoimmune disease. ${ }^{30}$ Both these aspects have important clinical implications for the design of antigen specific immunotherapies. To overcome this possible dilemma we investigated the contribution of two major uveitogenic proteins, S-Ag and IRBP, in the intranasal tolerising process. This study has demonstrated that combined S-Ag and IRBP nasal tolerance, in doses known to be effective individually, protect against RE induced EAU to the same extent as RE nasal tolerance, implying that these two antigens act as the major tolerogens to this form of uveoretinitis, despite the known uveitogenicity of other retinal antigens. In addition, intranasal tolerisation with IRBP or $\mathrm{S}-\mathrm{Ag}$ protects against RE induced EAU to the same extent as RE tolerisation but RE tolerisation only protects against $\mathrm{S}-\mathrm{Ag}$ induced disease and not IRBP induced disease (Dick et al ${ }^{6}$; Table 1), which implies perhaps that IRBP is a dominant antigen in our model. In this latter group there was a significantly raised total antibody response, predominantly IgG2a, 7 days after immunisation (Fig 1). This antibody response may be explained by the fact that animals tolerised with $\mathrm{RE}$ demonstrate a raised antiretinal antigen-antibody response before immunisation (Dick, unpublished data) and thus 7 days after immunisation an accelerated antibody response occurs as a result of antigen 
presentation of B cells in regional lymph nodes of treated animals. Whether this predominant anti-IRBP IgG2a response abrogates tolerance or is a consequence of the immunodominance of IRBP has yet to be defined. An alternative explanation is the relative low doses of antigens in RE capable of inducing EAU if administered alone-for example, S-Ag, so that IRBP tolerisation blocks IRBP component of RE induced EAU and the dose of S-Ag or other uveitogenic antigens within $\mathrm{RE}$ are inadequate to induce disease. This explanation in part is true, as the doses of IRBP within RE are not enough to induce consistent inflammatory response in EAU if administered as a single antigen. However, RE contains $25-50 \mu \mathrm{g}$ of S-Ag which is still sufficient for the induction of EAU. In addition, RE immunisation induces a primary immune response against IRBP and therefore IRBP sensitisation and generation of $\mathrm{CD}^{+} \mathrm{T}$ cells after RE immunisation does occur. ${ }^{19}$ Also, the tolerising doses of both S-Ag and IRBP when used alone are similar to tolerogenic doses within RE, and therefore should be expected to induce suppression unless competition for local antigen presentation in the nasorespiratory mucosa prevents this. If the results could be explained purely on a dose effect then one would not expect IRBP to suppress RE induced disease, contrary to our findings. To further understand these results we examined another potent antigen, MBP, which is unrelated to both EAU and RE. We found that MBP was unable to suppress RE induced EAU, while both S-Ag and IRBP inhibited RE induced histological disease. Induction of tolerance in this model appears therefore to be retinal antigen specific. A potential explanation, which requires further investigation of why both S-Ag and IRBP can induce suppression of RE induced EAU despite the presence of other retinal antigens in RE may be via the generation of antigen specific suppressor cells (against the tolerising antigen - that is, either $\mathrm{S}-\mathrm{Ag}$ or IRBP $)^{2331}$ which in turn upregulate inhibitory cytokines regulating $\mathrm{T}$ cell activation to other antigens (for example, non-tolerised antigen present in immunising RE). ${ }^{142}$ That is, both an initial antigen specific suppression and bystander suppression occur. Both these mechanisms occur during oral tolerance, ${ }^{15}$ and we are presently investigating the role of bystander suppression in intranasal tolerance. In other models, double tolerance has been described to more than one autoimmune disease related autoantigen, which is antigen specific and involves upregulation of TGF- $\beta{ }^{8}$

Our work demonstrates that not only does a combination of the two major retinal antigens, S-Ag and IRBP, confer the same level of protection from EAU as RE when given intranasally before immunisation but, in this model, tolerance is antigen specific and possibly generates a non-specific suppression of other retinal antigens (bystander response). This finding has important therapeutic implications; firstly, the use of purified proteins has potential advantages over whole retinal extract preparations with respect to bioactivity, sterility, and antigen dosage, particularly as only microgram quantities are required for effective nasal tolerance induction. Secondly, repetitive administration of a single antigen, if bystander suppressive mechanisms are induced, may be sufficient to maintain suppression of other retinal autoantigens but only if the initial tolerising antigen administered was the same as the active uveitogenic antigen. This may potentially overcome the problems of epitope spreading that we discussed above. This work further emphasises that intranasal administration of ocular antigens is a potential antigen specific and non-toxic alternative to current treatment for patients with uveitis.

This work was supported by the Leverhulme Trust.

1 Dick AD. Experimental approaches to specific immunotherapies in autoimmune disease: future treatment of
endogenous posterior uveitis? $\mathrm{Br} \mathcal{F}$ Ophthalmol 1995;79:818 .

2 Forrester JV, Liversidge J, Dua HS, Towler H, McMenamin Forrester JV, Liversidge J, Dua HS, Towler H, McMenamin
PG. Comparison of clinical and experimental uveitis. Curr Eye Res.1990;9:75-82.

3 Nussenblatt RB, Rodrigues MM, Walker WB, Cevario SJ, Salinas-Carmara MC, Gery I. Cyclosporin A: inhibition of experimental autoimmune uveitis in Lewis rat. F Clin Invest 1981;67:1228-332.

4 Vrabec TR, Gregerson DS, Dua HS, Donoso LA. Inhibition of experimental autoimmune uveoretinitis by oral administration of S-Ag and synthetic peptides. Autoimmunity 1992; 12:175-84.

5 Nussenblatt RB, Caspi RR, Mahdi R, Chan CC, Roberge F, Lider $\mathrm{O}$, et al. Inhibition of $\mathrm{S}-\mathrm{Ag}$ induced experimental autoimmune uveoretinitis by oral induction of tolerance with S-Ag. F Immunol 1990;144:1689-95.

6 Dick AD, Cheng YF, McKinnon A, Liversidge J, Forrester JV. Nasal administration of retinal antigens suppresses the inflammatory response in experimental allergic unflammatory response in experimental allergic uveoretinitis: a preliminary report of intranasal induction of
tolerance with retinal antigens. Br f Ophthalmol 1993;77: tolerance

7 Dua HS, Donoso LA, Laibson PR. Conjunctival instillation of retinal antigens induces tolerance. Ocular Immunol Inflamm 1994;2:29-36.

8 Wang ZY, He B, Qiao J, Link H. Suppression of experimental autoimmune myasthenia gravis and experimental allergic encephalomyelitis by oral administration of acetylcholine receptor and myelin basic protein: double tolerance. F Neuroimmunol 1995;63:79-86.

9 Thompson HSG, Harper N, Bevan DJ, Staines NA. Suppression of collagen induced arthritis by oral administration of type II collagen: changes in immune and arthritic responses mediated by active peripheral suppression.
Autoimmunity 1993;16:189-99.

10 Lider O, Santos LMB, Le CYS, Higgins PJ, Weiner HL. Suppression of EAE by oral administration of myelin basic protein: suppression of the disease and in vitro immune protein: suppression of the disease and in vitro immune
responses is mediated by antigen-specific $\mathrm{CD} 8^{+}$cells. $\mathcal{F}$ responses is mediated by antig
Immunol $1988 ; 142: 1748-53$.

11 Mowat AM. The regulation of the immune response to dietary protein antigens. Immunol Today 1987;8:93-5.

12 Holt PG, Sedgwick J. Suppression of IgE responses following inhalation of antigens. Immunol Today 1987;8:14-5.

13 Melamed D, Friedman A. Direct evidence for anergy in T lymphocytes tolerised by oral administration of ovalbumin. Eur F Immunol 1993;23:935-42.

14 Khoury SJ, Hancock WW, Weiner HL. Oral tolerance to myelin basic protein and natural recovery from experimental autoimmune encephalomyelitis are associated with down regulation of inflammatory cytokines and differential upregulation of transforming growth factor beta, interleukin 4 , and prostaglandin E expression in the brain. $\mathcal{F}$ Exp Med 1992;176:1355-64.

15 Wildner G, Thureau SR. Orally induced bystander suppression in experimental autoimmune uveoretinitis occurs only in the periphery and not in the eye. Eur F Immunol 1995;25:
1292-7.

16 Gregerson DS, Obritsch WF, Donoso LA. Oral tolerance in experimental autoimmune uveoretinitis: distinct mechanisms of resistance are induced by low dose vs high dose feeding protocols. F Immunol 1993;151:5751-61.

17 Garside P, Steel M, Liew FY, Mowat AM. CD4 ${ }^{+}$but not $\mathrm{CD}^{+} \mathrm{T}$ cells are required for the induction oral tolerance. Int Immunol 1995;7:501-4.

18 Weiner HL, Mackin GA, Matsui M, Orav EJ, Khoury SJ, Dawson DM, et al. Double-blind pilot trial of oral tolerisation with myelin antigens in multiple sclerosis. Science 1993;259:1321-3.

19 Dick AD, Cheng YF, Liversidge J, Forrester JV. Intranasal administration of retinal antigens suppresses retinal administration of retinal antigens suppresses retinal
antigen-induced experimental autoimmune uveoretinitis. antigen-induced experimental
Immunology 1994;82:625-31.

20 Kamrandt T, Soloway PD, Perkins DL, Gefter ML. Pertussis toxin prevents the induction of peripheral $\mathrm{T}$ cell anergy 
and enhances the $\mathrm{T}$ cell response to an encephalitogenic peptide of myelin basic protein. F Immunol 1991;147:32964002 .

21 Chen Y, Inobe JI, Kuchroo VK, Baron JL, Janeway Jr CA, Weiner HL. Oral tolerance in myelin basic protein $\mathrm{T}$ cell receptor transgenic mice: suppression of autoimmune encephalomyelitis and dose dependent induction of regulatory cells. Proc Nat Acad Sci (USA) 1996;93:338-91.

2 Rizzo LV, Miller-Rivero NE, Chan C-C, Wiggert B, Nussenblatt RB, Caspi RR. Interleukin-2 treatment potentiates induction of oral tolerance in a murine model of autoimmunity. F Clin Invest 1994;94:1668-72.

23 Rizzo LV, Caspi RR. Immunotolerance and prevention of ocular autoimmune disease. Curr Eye Res 1995;14:854-64.

24 Chen Y, Kuchroo VK, Inobe J, Hafler DA, Weiner HL. Regulatory $\mathrm{T}$ cell clones induced by oral tolerance: suppression of autoimmune encephalomyelitis. Science 1994;265:1237-40.

25 Chen Y, Inobe JI, Marks R, Gonnella P, Kuchroo VK, Weiner HL. Peripheral deletion of antigen-reactive T cells in oral tolerance. Nature 1995;376:177-80.

26 Metzler B, Wraith DC. Inhibition of experimental autoimmune encephalomyelitis by inhalation but not oral admin stration of the encephalitogenic peptide: influence of MHC binding affinity. Int Immunol 1993;5:1159-65.

27 McMenamin C, Oliver J, Girn B, Holt BJ, Kees VR, Thomas WR, et al. Regulation of T-cell sensitisation at epithelial surfaces in the respiratory tract: suppression of $\operatorname{IgE}$ responses to inhaled antigens by $\mathrm{CD} 3+\mathrm{TcR} \alpha^{-} / \beta^{-}$lymphocytes (putative $\gamma / \delta$ cells). Immunology 1991;74:234-9. 8 McMenamin C, Primm C, McKersey M, Holt PG. Regulation of IgE responses to inhaled antigens in mice by antigen-specific gamma delta T cells. Science 1994;265: 1869-70.

29 Melamed D, Friedman A. In vivo tolerisation of Th1 lymphocytes following a single feeding with ovalbumin: anergy in the absence of suppression. Eur f Immunol 1994; 24:1974-81

30 McRae BL, Vanderlugt CL, Dal Canto MC, Miller SD. Functional evidence for epitope spreading in the relapsing pathology of experimental autoimmune encephalomyelitis. pathology of experimed 1995;182: 5-85.

31 Dick AD, Cheng YF, Liversidge J, Forrester JV. Immunomodulation of experimental autoimmune uveoretinitis: a mode of tolerance induction with retina antigens. Eye 1994;8:52-9. 